\title{
OS HALITI-PARESÍ: UMA REFLEXÃO SOBRE SAÚDE E DEMOGRAFIA DA POPULAÇÃO RESIDENTE NAS TERRAS INDÍGENAS PARESÍ
}

\author{
ANA CLÁUdIA PEREIRA TERÇAS ${ }^{1}$ \\ UNEMAT/FIOCRUZ
}

VAGNER FERREIRA DO NASCIMENTO ${ }^{2}$

UNEMAT

THALISE YURI HATTORI ${ }^{3}$

UNEMAT

LEONIR EVANDRO ZENAZOKENAE ${ }^{4}$

UNEMAT

MARINA ATANAKA ${ }^{5}$

UFMT

ELBA REGINA SAMPAIO DE LEMOS ${ }^{6}$

FIOCRUZ

\begin{abstract}
RESUMO: As comunidades haliti-paresí destacam-se em Mato Grosso pela busca constante de sua sustentabilidade e etnodesenvolvimento. Com o objetivo de conhecer algumas características culturais da saúde e aspectos demográficos, realizou-se um estudo quantitativo e descritivo dividido em duas etapas. Na primeira, uma revisão de literatura que abordou as características histórico-sociais e culturais da saúde do povo Haliti-Paresí; posteriormente, com base nos dados do censo do IBGE de 2010, pôde-se identificar os aspectos demográficos
\end{abstract}

\footnotetext{
1 Doutoranda em Medicina Tropical pelo Instituto Oswaldo Cruz, Laboratório de Hantaviroses e Ricketsioses (Fundação Oswaldo Cruz), mestre em Saúde Coletiva pela Universidade Federal de Mato Grosso e professora do curso de Enfermagem da Universidade do Estado de Mato Grosso, campus de Tangará da Serra. E-mail: ana.claudia@unemat.br.

2 Doutorando em Bioética pelo Centro Universitário São Camilo, Mestre em Terapia Intensiva pela Universidade de Brasília e professor do curso de Enfermagem da Universidade do Estado de Mato Grosso, campus de Tangará da Serra. E-mail: vagnerschon@ @otmail.com .

${ }^{3}$ Mestre em Ciências da Saúde pela Universidade Federal da Grande Dourados e professora do curso de Enfermagem da Universidade do Estado de Mato Grosso, campus de Tangará da Serra. E-mail: thalisehattori@gmail.com.

${ }^{4}$ Indígena haliti-paresí e acadêmico de Enfermagem da Universidade do Estado de Mato Grosso, campus de Tangará da Serra. E-mail: evandrozenazokenae@gmail.com .

${ }^{5}$ Doutora em Saúde Pública pela Escola Nacional de Saúde Pública e professora adjunta do Instituto de Saúde Coletiva da Universidade Federal de Mato Grosso. E-mail: marina.atanaka@gmail.com .

${ }^{6}$ Doutora em Medicina Tropical e pesquisadora do Laboratório de Hantaviroses e Ricketsioses do Instituto Oswaldo Cruz (Fundação Oswaldo Cruz). E-mail: elemos@ioc.fiocruz.br .
} 
dessa população. Em seu processo histórico, a interação e integração com as novas realidades propiciaram que construíssem seu cotidiano nos moldes do etnodesenvolvimento. As práticas de saúde são realizadas na perspectiva holística, permeada por elementos mágicos e míticos da medicina tradicional indígena com vistas a integrar os cuidados com a medicina ocidental. $O$ crescimento populacional reflete o processo de "etnogênese" no Brasil, com predomínio do sexo masculino, taxa de alfabetização de $81 \%$ e grande porcentagem de indígenas com registro de nascimento civil. Metade da população não possui renda e suas condições de moradia retratam duas realidades que contrapõem-se.

PALAVRAS-CHAVE: saúde; demografia; população indígena.

ABSTRACT: The Haliti-Paresí communities stand out in Mato Grosso by the constant pursuit of its sustainability and ethnodevelopment. In order to meet some of the cultural characteristics of health and demographics, it sought through quantitative and descriptive study carried out it in two steps. At first, a literature review that addressed the social and cultural historical characteristics of health Haliti-Paresi people and then based on the 2010 IBGE census data can identify the demographics of this population. In its historical process, interaction and integration with the new realities have led them to build their daily lives in ethnodevelopment templates. Health practices are held at the holistic perspective, permeated with magical and mythical elements of traditional indigenous medicine in order to integrate care with Western medicine. Population growth reflects the process of "ethnogenesis" in Brazil, with a predominance of male literacy rate of $81 \%$ and large percentage of Indians with civil birth registry. Half the population has no income and their housing conditions depict two realities that opposes.

KEYWORDS: health; demographics; indigenous population.

\section{Introdução}

A diversidade de povos, culturas, línguas faladas e distribuição geográfica das populações indígenas brasileira faz com que a produção de conhecimento seja um desafio e constitua-se em um campo de dimensões plurais que deve ser estimulado (PAGLIARO, AZEVEDO e SANTOS, 2005).

De acordo com o censo realizado em 2010, no Brasil existem 817.963 indígenas e em Mato Grosso residem 42.538 índios, que são atendidos pelo Distrito Sanitário Especial Indígena (DSEI) Cuiabá, DSEI Xavante, DSEI Vilhena, DSEI Xingú, DSEI Kaiapó do Mato Grosso e DSEI Araguaia (IBGE, 2012).

Os indígenas mato-grossenses estão distribuídos em territórios demarcados e alguns mudaram de território e habitam hoje o Parque 
Indígena do Xingú. Cabe ressaltar que o estado não possui o maior contingente populacional de indígenas, porém conta com a maior diversidade de povos indígenas do país.

Neste contexto, devem ser empreendidos esforços para a realização de estudos que busquem descrever os diferentes aspectos dessas comunidades, ampliando-se, assim, o conhecimento sobre essas populações e, consequentemente, fornecendo instrumentos para gestão de suas necessidades e melhoria da qualidade de vida dos mesmos.

A etnia Haliti-Paresí destaca-se em Mato Grosso, pela sua interação sociopolítica, pelos constantes avanços em seu etnodesenvolvimento e bom relacionamento com os não índios. Estudos antropológicos já foram conduzidos com essas comunidades, porém ainda não discutiu-se sobre seus aspectos demográficos (COSTA, 1985; PEREIRA 1986 e 1987; MACHADO, 1994; BORTOLETTO, 1999; CANOVA, 2001, BORGES, 2009; SCHIMIDT, 2011 ; SILVEIRA, 2011 ).

As aldeias dos Haliti-Paresí, localizadas na região do médio-norte mato-grossense, estão concentradas nos municípios de Tangará da Serra, Campo Novo do Parecis, Sapezal, Diamantino, Nova Marilândia, Conquista do Oeste e Barra do Bugres. Essa área compõe a região cortada pela BR-364, rodovia que liga Cuiabá a Porto Velho (CANOVA, 2001).

Como a Haliti-Paresí é a principal etnia da região médio-norte do estado, faz-se necessário conhecer algumas características de sua cultura e de suas práticas de saúde, bem como os principais aspectos demográficos, tendo em vista que estas informações poderão subsidiar ações de promoção da saúde e melhoria de qualidade de vida dos Haliti-Paresí.

\section{Metodologia}

O presente estudo foi constituído com base nos dados disponíveis no censo do Instituto Brasileiro de Geografia e Estatística (IBGE) e na pesquisa sobre publicações relacionadas ao povo Haliti-Paresí.

A partir de uma abordagem quantitativa e descritiva, no presente estudo foram incluídos os dados produzidos pelo censo do IBGE 
realizado em 2010 que se encontravam disponíveis on-line. A coleta de dados foi realizada aos pares no mês de agosto de 2015, utilizando-se uma planilha eletrônica para digitação manual das informações disponíveis no IBGE - informações sobre população autodeclarada indígena-. Para tanto, foi construído um instrumento de coleta de dados com informações das terras indígenas de acordo as variáveis em estudo (distribuição populacional por sexo, língua falada, escolaridade, acesso ao registro de nascimento, renda e condições sanitárias). Após a consolidação da base de dados, um terceiro pesquisador realizou a conferência das informações e, posteriormente, a mesmas foram importadas para o SPSS (versão 20.0) para realização das análises estatísticas.

Adicionalmente foi realizada uma revisão de literatura na qual foram destacadas as principais características histórico-sociais e culturais da saúde do povo Haliti-Paresí. Para este processo, foram consultados, em agosto de 2015, artigos científicos, livros, teses e dissertações nos quais essa população foi descrita, sem qualquer limitação quanto à área específica de conhecimento. Utilizou-se como descritores as palavras "paresí", "pareci", "haliti", "aliti" "índios de Mato Grosso" nas bases de dados da Scielo e PubMed. Após leitura e fichamento do material selecionado por dois pesquisadores, os artigos e textos, entre outros produtos correlatos, foram submetidos à discussão com o grupo de pesquisa, constituído por bolsistas de iniciação científica e docentes pesquisadores - tanto enfermeiros como médicos e biólogos -, totalizando treze envolvidos, além de um integrante da etnia objeto deste estudo.

As informações obtidas são apresentadas de forma analítica, considerando os aspectos demográficos da população haliti-paresí para cada terra indígena em que residem, assim como as variáveis de distribuição populacional por sexo, língua falada, escolaridade, acesso ao registro de nascimento, renda e condições sanitárias.

\section{Resultados e discussão}

\section{Conhecendo o povo Haliti-Paresí}


Os Paresí se autodenominam Haliti (povo) e habitam desde tempos imemoriais a região do Chapadão do Parecis (RONDON, 1910; MACHADO, 1994; ROQUETTE-PINTO, 2005). Atualmente a denominação utilizada é Haliti-Paresí, termo este que é uma junção do nome que utilizam entre eles e termo ao Paresí, que foi concedido pelos colonizadores.

O povo indígena Haliti-Paresí tem origem mítica na região de Ponte de Pedra e, de acordo com suas crenças, foi de dentro dessa grande pedra onde moravam seres humanos que saíram os grupos paresí. Foi o pica-pau-anão e a arara que abriram a pedra e assim saiu Wazare, chefiando este povo. Eram divididos em subgrupos - Waimaré, Kaxiniti, Kozarini, Warere e Kawali - que até o contato externo habitam regiões definidas dentro do território paresí, normalmente em cabeceira de rios da região (SILVEIRA, 2011).

A língua tradicional dos Paresí pertence ao tronco Aruak é caracterizada por Schmidt (2011) como pertencente a grupos que apresentam contrastes na relação com outras culturas e que podem apresentar traços dominantes ou submissos, tornando-se, assim, dóceis ou "índios bravos", o que explica a diversidade de comportamento dos subgrupos no contato com a expedição de Rondon (1907-1930), já que alguns indígenas o seguiram e serviram de mão de obra, enquanto outros se mantiveram afastados mantendo seus costumes.

Após o contato com as expedições para a instação das linhas telegráficas, vieram as missões religiosas, a exploração seringueira, a extração da poaia e as sucessivas frentes expansionistas, seguidas pela aberturas de rodovias, criação de gado e expansão agrícola, incentivadas pelos programas governamentais com objetivo de tornar o cerrado um espaço produtivo (CANOVA, 2001; OLIVEIRA, 2004). Como consequência, ocorreu uma interação dos diferentes subgrupos halitiparesí, fato que, além de fazê-los considerar a si mesmos uma grande "família", justifica atualmente a inexistência de aldeias com populações puramente waimaré, kozarini, etc.

Essa interação foi incentivada em decorrência da redução brusca da população neste período histórico, uma vez que este povo possuía cerca de 20 mil integrantes que em poucos anos foram reduzidos a 350 
indivíduos. Foram necessários diversos esforços para preservar sua história, costumes, território e descendentes.

Na década de 1960, com a criação da estrada BR 364 e todas as facilidades e comodidades que a estrutura traria, foi criada a aldeia Rio Verde, que cresceu e ajudou outras aldeias a se reconstruírem, desencadeando posteriormente as lutas pelas terras que hoje integram o território paresí (SILVEIRA, 2011).

A Terra Indígena Paresí foi a primeira a ser garantida. A partir daí, já na década de 1990, inicia-se o processo de interiorização das terras: algumas famílias fundadoras da aldeia Rio Verde mudaram-se para o interior das terras a fim de fortalecer a busca pela homologação do território, fundando outras aldeias em todo o território paresí, como as aldeias Utiairiti, Sacre 2 e Wazare (MACHADO, 1994; COSTA-FILHO, 1996; BORTOLETO, 1999).

O território paresí possui atualmente 1.120.369,5 hectares, distribuídas em 56 aldeias em nove terras que se encontram em fases diferentes de homologação (Tabela 1).

$\mathrm{Na}$ atualidade, o espaço geográfico onde estão localizadas as terras dos Haliti-Paresí é o local mais desejado pelo agronegócio. Constituído por extensas lavouras mecanizadas de monocultura, o território dos Haliti-Paresí abriga grandes potenciais hídricos para a geração de energia elétrica, constituindo, assim, um importante e estratégico aspecto sob o ponto de vista regional do Programa de Aceleração do Crescimento (PAC) de 2010 (SILVEIRA, 2011).

Desde as últimas décadas, projetos de "etnodesenvolvimento" têm sido utilizados pela comunidade como tentativa de fornecer condições e possibilidades que cada momento histórico suscita. Neste contexto, os Haliti-Paresí têm buscado sua autonomia política e suporte de suas necessidades materiais e simbólicas.

Em seu estudo sobre o etnodesenvolvimento, Silveira (2011) destaca que este grupo indígena busca, independente da Fundação Nacional do Índio (Funai), preparar gestores qualificados que possam refletir e discutir sobre o destino do grupo. Como estratégias, almejam aprender inglês, informática, conhecer e organizar os trâmites do setor financeiro e jurídico, além de dominar os projetos políticos, como ferramentas para gerenciar os recursos que entram através dos 
empreendimentos, aproveitando os benefícios do meio ambiente identificados em seus territórios.

Tabela 1 - Relação de área, situação jurídica e localização das terras indígenas halitiparesí

\begin{tabular}{|c|c|c|c|}
\hline $\begin{array}{c}\text { TERRA } \\
\text { INDÍGENA }\end{array}$ & ÁREA & $\begin{array}{l}\text { SITUAÇÃO } \\
\text { JURÍDICA }\end{array}$ & LOCALIZAÇÃO \\
\hline PARESÍ & $563.586,5$ ha & Homologada & $\begin{array}{c}\text { Tangará da Serra e } \\
\text { Sapezal }\end{array}$ \\
\hline UTIARITI & $412.304,2$ ha & Homologada & Campo Novo do Parecis \\
\hline $\begin{array}{c}\text { RIO } \\
\text { FORMOSO }\end{array}$ & $19.794,5$ ha & Homologada & Tangará da Serra \\
\hline JUININHA & $70.537,5$ ha & Homologada & Tangará da Serra \\
\hline ESTIVADINHO & $2.031,9$ ha & Homologada & Tangará da Serra \\
\hline FIGUEIRAS & $9.858,9$ ha & Homologada & $\begin{array}{l}\text { Tangará da Serra e } \\
\text { Pontes e Lacerda }\end{array}$ \\
\hline UIRAPURU & $21.700,0$ ha & Homologada & $\begin{array}{l}\text { Campos de Julho e } \\
\text { Conquista D’oeste }\end{array}$ \\
\hline $\begin{array}{l}\text { PONTE DE } \\
\text { PEDRA }\end{array}$ & $17.000,0$ ha & $\begin{array}{l}\text { Identificada e } \\
\text { delimitada }\end{array}$ & Campo Novo do Parecis \\
\hline $\begin{array}{l}\text { ESTAÇÃO } \\
\text { PARESÍ }\end{array}$ & $3.620,8$ ha & $\begin{array}{l}\text { Delimitada (Sub } \\
\text { Júdice) }\end{array}$ & $\begin{array}{c}\text { Diamantino e } \\
\text { Nova Marilândia }\end{array}$ \\
\hline
\end{tabular}

Fonte: FUNAI (2010); Silveira (2011).

Atualmente a economia da comunidade é baseada na arrecadação do pedágio da BR 235, que liga os municípios de Campo Novo do Parecis e Sapezal, venda de artesanatos, exploração do turismo cultural e parceria para produção agrícola nos moldes de monocultura.

O cotidiano atual nas aldeias apresenta uma diversidade de ações, que ora remetem aos seus ritos e costumes e em outros momentos expressam a influência da cultura imuti (homem branco). A maioria dos homens e mulheres desempenha atividades na própria aldeia. São professores, agentes de saúde indígena, secretários das escolas, agentes indígenas sanitaristas, motoristas das unidades de saúde (CANOVA, 2001).

Aos homens cabe 0 trabalho nas lavouras, plantão para recebimento do pedágio, além da caça e da pesca e de trabalhos gerenciais na associação e na Funai. Ocorre, então, um deslocamento rotineiro para os centros urbanos mais próximo, que inclui, ainda, a 
busca por capacitação profissional, com inclusão em cursos de graduação em diversas áreas, sendo este último também exercido por mulheres.

A maioria das pessoas idosas recebe aposentadoria, mas mantêm o trabalho nas roças domésticas, realiza coletas de frutas e sementes, caça e pesca. As mulheres mais velhas, como descreve Silveira (2011), dedicam-se a pequenos afazeres, como costuras, fazer massa de biju, preparar a chicha, tecer redes com fibras de tucum ou linhas e barbantes industrializados, herança dos tempos de convivência com as irmãzinhas imaculadas do Internato Utiariti. Já as mulheres mais jovens, algumas se dedicam ao artesanato, outras se dedicam ao cuidado das casas e crianças. A divisão das atividades domésticas é negociada entre todos os membros da família de acordo com a aptidão pessoal.

Nos pátios das aldeias não há demarcação de ruas, os animais domésticos circulam livremente. A escola é quase a extensão das casas, pois toda comunidade, além das crianças, a frequenta, atuando como o local dos encontros de crianças e jovens para atividades de esporte, lazer, cursos e reuniões com visitantes (COSTA FILHO, 1996, BORTOLETO, 1999). Ressalta-se que, após o término do ensino fundamental em escola indígena, o adolescente é incentivado a dar continuidade nos estudos nas escolas dos municípios mais próximos. Assim, enfrentam horas de deslocamento terrestre e travessia de rios, o que demonstra a preocupação da comunidade com a educação.

As casas são denominadas de hatí; de forma ovalada, são construídas com madeiras, cobertas com palhas da palmeira guariroba e são habitadas por famílias celulares e nucleares. Em média, a hatí possui $12 \mathrm{~m}$ de comprimento, $6 \mathrm{~m}$ de largura, $3 \mathrm{~m}$ de altura e duram em média dez anos (Figura 1). Durante o dia, tornam-se um grande espaço social e à noite são organizadas para o repouso de todos com a distribuição das redes. Muitas famílias possuem camas, guarda-roupas, máquina de lavar, geladeira, fogão, aparelhos de som e televisão (OLIVEIRA, 1994; MACHADO, 2004).

Destaca-se o asseio que toda a comunidade tem com a hatí e demais locais da aldeia, esta fato foi descrito desde os primeiros contatos com os Haliti-Paresí, pois as mulheres estão sempre lavando os utensílios, roupas ou varrendo o chão da hatí (SILVEIRA, 2011). Essa 
preocupação com o ambiente é um comportamento específico de cada aldeia. Assim, aquela aldeia que conservou mais a cultura indígena preserva a limpeza e equilíbrio ambiental, enquanto que nas que incorporaram comportamentos imuti com maior intensidade verifica-se, de forma evidente, a presença mais frequente de lixo na aldeia.

Figura 1 - Estrutura da hatí em habitação (a) e em construção (b).

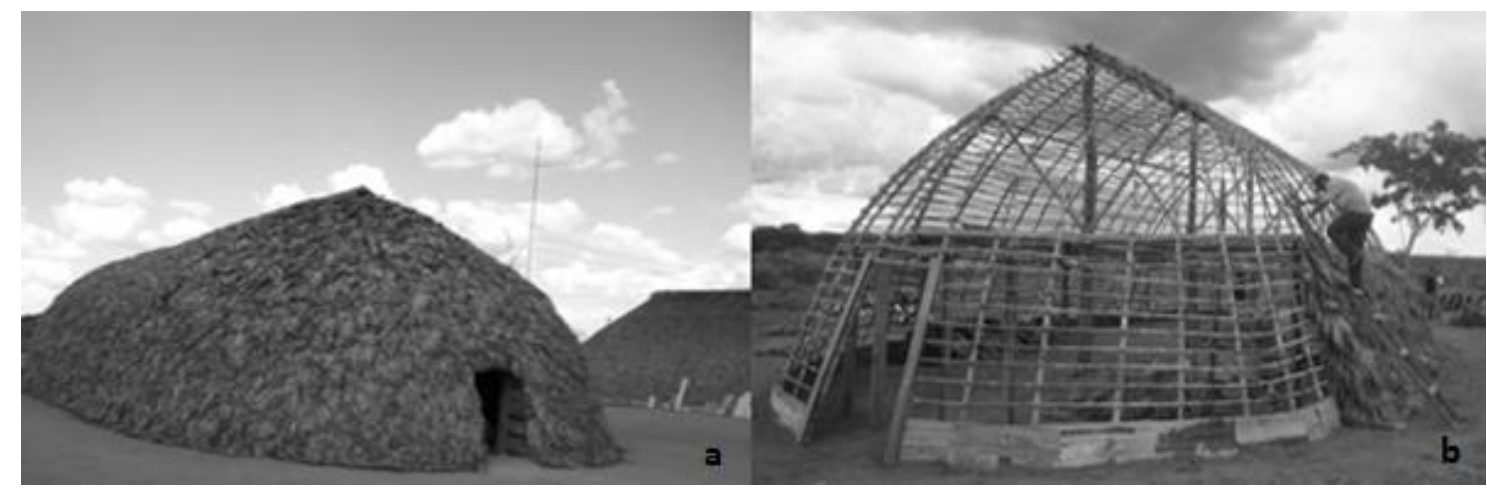

Fonte: Terças et al. (2014).

\section{Práticas e assistência à saúde na comunidade indígena haliti-paresí}

Desde os tempos anteriores à colonização, os povos indígenas utilizam seus sistemas tradicionais de saúde indígena, que evidenciam diferentes aspectos da sua organização social e da sua cultura, a partir do uso das plantas medicinais, rituais de cura e práticas diversas de promoção da saúde, sob a responsabilidade de pajés, curadores e parteiras tradicionais (BRASIL, 2007a).

As medicinas tradicionais indígenas obedecem a níveis de causalidade e itinerários terapêuticos distintos do modelo biomédico ocidental e procuram restabelecer o equilíbrio entre o indivíduo e o mundo. As medicinas tradicionais são diferentes, mas não menos importantes do que a medicina ocidental, e devem estar sempre presentes em qualquer trabalho de saúde com povos de culturas diferenciadas (FERREIRA, 2013).

Estes sistemas médicos xamânicos não possuem limites definidos entre os diferentes subsistemas que formam um determinado universo 
sociocultural. O conjunto de saberes e de práticas que promovem saúde previne e cura doenças e está associado à religião, à política, à economia e à arte, entre outros fatores (BRASIL, 2007a).

Em estudo histórico realizado por Sá (2009) na sociedade matogrossense do século XVIII, os indígenas já foram descritos como praticantes de magia e feitiçaria e denunciados às autoridades coloniais da época. Este relato reflete o cotidiano da atenção à saúde e prática de medicina tradicional indígena nas comunidades indígenas de Mato Grosso.

Os Haliti-Paresí também trazem ao longo da sua história as práticas de medicina tradicional indígena. A saúde é pautada em sua cultura e definida como estar bem com o corpo e também com os espíritos. Relata-se que quando uma pessoa fica doente, a primeira providência a ser tomada é ver se está tudo bem com parte espiritual do indígena (MORAIS, 2003). Todo o tratamento de saúde está pautado na magia e no misticismo, sendo o espírito do bem denominado de hutyhaliti (sábio, curador ou rezador) e a personificação do mal conhecida por thihanare (espírito do mal, os curadores que praticam maldade) (SILVEIRA, 2011 ).

A personificação dos espíritos acontece através das flautas, tidas como instrumentos sagrados, cujo som os evoca. No mundo dos sonhos também ocorre a manifestação dos espíritos e somente os homens sábios podem visualizá-los. Assim, por gerações esses indígenas cuidam e cultuam as flautas sagradas, respeitando suas manifestações tanto no mundo dos sonhos como nas celebrações em grupo (MORAIS, 2003).

Segundo Silveira (2011), a proteção das flautas atua em vários pontos da vida, desde proteção à saúde, cura, sendo escudo contra as forças ruins, até proteção contra a interferência de Tinahare, o elemento que desencadeia o mal. $O$ cuidado com as flautas é realizado pelas famílias, que quando não o fazem, podem estar suscetíveis às desgraças, misérias, doenças, brigas e todo tipo de desavença.

A etno-história desse povo descreve que Kamaihiye, o mais jovem dos irmãos que saiu Ponte de Pedra, detinha poderes mágicos (PEREIRA 1986 e 1987). Ele criou as plantas curativas, tinha dons divinatórios e ensinou os segredos da cura do corpo e da alma aos Haliti-Paresí. Estes 
segredos estão guardados nas diversas plantas, raízes e ervas que possuem locais específicos de serem encontrados (COSTA, 1985; COSTA FILHO, 1996).

O conhecimento tradicional paresí abrange essas dimensões de forma articulada com a natureza, extraindo dela os elementos fundamentais para que a cura seja efetivada. Nesse sentido, é buscada uma harmonia entre corpo, espírito e natureza para que haja equilíbrio e garantia de uma permanência saudável para o indivíduo e para a comunidade (BORGES, 2009).

A medicina ocidental está associada às funções e disfunções biológicas, sem preocupação com fatores culturais, que têm reflexo no sucesso de prevenção e tratamento de agravos de saúde (BUCHILLET, 1991). Diferentemente desta, o saber indígena é alicerçado em uma perspectiva holística, permeada por elementos mágicos e míticos, com aplicabilidade prática comprovada por inúmeras gerações.

Os Haliti-Paresí entendem o "mal" como doenças, vinganças, invejas, disputas, morte, miséria, ódio, raiva, energia negativa (SILVEIRA, 2011). Assim, diversos são os motivos para que os pajés atuem o universo das práticas mágicas e curativas, não sendo restrito ao mundo masculino. As mulheres se revelaram as guardiãs da memória das histórias, assim como dos conhecimentos e do trato com o poder de ervas (BORTOLETO, 2005).

Botelho e Costa (2006) destacam que os pajés sofreram grandes perseguições durante o processo de colonização, pois realizavam funções sagradas que podiam influenciar politicamente seus grupos sociais. Estes sempre mantiveram suas atividades relacionadas à cura, mesmo que em menor intensidade, e ao final de quatro séculos de desvalorização apresentaram uma capacidade admirável de reconstruir os próprios saberes.

Os pajés e/ou xamãs do povo Haliti-Paresí também vivenciaram esse mesmo processo descrito acima e atualmente a execução da medicina tradicional indígena acontece paralelamente à assistência prestada pelos profissionais de saúde que atuam nas aldeias. Porém, esta não é interativa, articulada e eficaz, em decorrência da alta rotatividade de profissionais, após a centralização da assistência à saúde indígena ocorrida em 2011. 
Ferreira (2013) relata que os sistemas médicos indígenas e o sistema oficial de saúde devem articular-se de forma a contribuir para qualificar a atenção prestada aos povos indígenas, pois necessitam de uma construção conjunta entre profissionais de saúde e comunidades indígenas que objetive um cuidado integral à saúde.

O curandeiro que atua no território paresí trata das doenças tanto do espírito como do corpo dos doentes com folhas ou raízes e as doenças não espirituais são tratadas pelos agentes de saúde, que são índios que trabalham nos postos de saúde situados nas aldeias. Assim, o curandeiro cuida de "doença de índio" e os profissionais de saúde tratam de "doenças de não índio" (BORGES, 2009).

Há décadas os povos indígenas do Brasil discutem as políticas a serem implementadas para assegurar-lhes vida e saúde (GARNELO e PONTES, 2012). Durante este período, foram muitas as mobilizações do movimento indígena e das organizações que atuam no campo da saúde, com o objetivo de exigir que o Estado brasileiro estruture políticas que possibilitem a atenção diferenciada aos povos indígenas (ALTINI et al., 2013).

O início da organização política no Brasil para a saúde indígena deu-se em 1910, através do Serviço de Proteção aos Índios (SPI). Porém, após diversas reinvindicações por parte das lideranças indígenas, foi criado, em 1950, o Serviço de Unidades Sanitárias Aéreas (SUSA), vinculado ao Ministério da Saúde, que tinha como objetivo prestar assistência em áreas de difícil acesso com foco na vacinação, atendimento odontológico, controle de tuberculose e outras doenças transmissíveis (SANTOS et al., 2008; BRITO e LIMA, 2013).

Em 1967 surge a Fundação Nacional do Índio (Funai), em substituição ao SUSA (BRASIL, 2006). Equipes volantes prestavam assistência de forma esporádica às comunidades indígenas.

Somente após a promulgação da Constituição Federal de 1988, em que houve mudança de paradigma, definindo a necessidade do respeito à especificidade cultural e social de cada povo, que foi possível caminhar em direção à implementação do novo modelo de atenção à saúde indígena, de forma compartilhada entre Ministério da Saúde, através da Fundação Nacional da Saúde (Funasa) e da Funai (ALTINI et al., 2013). 
Até o ano de 1991 as ações eram focadas apenas no atendimento às demandas de pessoas doentes que procuravam as equipes volantes. A partir da consolidação da Lei Arouca, que, em 1999, regulamentou a implantação de um sistema de atenção diferenciada à saúde dos indígenas, foram criados os Distritos Sanitários Especiais Indígenas (DSEls). Foram implantados então 34 DISEls, distribuídos por todas as regiões do país (BRASIL, 2002).

Grande ponto de discussão nesse processo foi a gestão dos DSEls, inicialmente executados através de convênios firmados com organizações da sociedade civil, como as organizações indígenas, indigenistas ou diretamente com alguns municípios. A política nacional da saúde indígena foi regulamentada através da Portaria $n^{\circ} .254$ em 31 de janeiro de 2002 com o propósito de garantir o acesso à atenção integral à saúde, de acordo com os princípios e diretrizes do Sistema Único de Saúde, contemplando a sua diversidade social, cultural, geográfica, histórica e política (BRASIL, 2002; MARTINS, 2013).

Em 2004, a Funasa buscou recuperar e execução direta dos serviços de saúde e reduzir a ação das entidades conveniadas. Em 2007, com a edição da Portaria $n^{\circ}$. 2.656, o poder na gestão da Funasa foi fortalecido e a municipalização da saúde indígena foi proposta, ação esta contrária aos interesses das lideranças indígenas (ATHIAS e MACHADO, 2001; ATHIAS, 2005).

Diversos movimentos indígenas foram realizados nos espaços de controle social na busca pela efetivação de uma política pública para a saúde dos povos indígenas, que atendesse suas necessidades e especificidade, até que em 2010 foi criada a Secretaria Especial de Saúde Indígena (Sesai), assumindo, assim, a função da Funasa (MARTINS, 2013).

Em 2011, a Sesai selecionou entidades privadas sem fins lucrativos para executar a atenção à saúde indígena por meio de convênios. As entidades selecionadas foram a Sociedade Paulista para o Desenvolvimento da Medicina (SPDM), responsável por 14 DSEls, o Instituto Materno Infantil de Pernambuco (IMIP), responsável por 5 DSEls, e a Missão Evangélica Caiuá, com sede em Dourados, responsável por 15 DSEls. Esta concentração enorme de recursos e responsabilidades sobre as ações da saúde indígena em apenas três 
organizações, assim como a falta de transparência na execução deste modelo de relação convenial, passaram a ser motivo de duras críticas do movimento indígena em todo o país (ALTINI et al., 2013).

Os primeiros serviços de saúde nas terras indígenas paresí foram realizados por missionários, pelo SPI, pelas equipes volantes de saúde da Funai e por outros que pregavam uma saúde diferente daquela que os Haliti-Paresí tinham. Essa interferência e fragmentação das equipes volantes explicitou a necessidade de uma articulação com equipes de saúde em nível local e/ou regional, engajadas num trabalho de médio e longo prazo, referenciado em serviços permanentes de maior resolução e complexidade do próprio sistema geral de saúde (BORGES, 2009). Dessa forma, a comunidade haliti-paresí não dispunha de modelo de assistência à saúde das populações indígenas que atendesse às suas necessidades específicas e diferenciadas.

Neste contexto político, os Haliti-Paresí, preocupados com a saúde do seu grupo, em reunião do Conselho Distrital de Saúde Indígena (Condisi), propõem assumir o gerenciamento da saúde através da organização sociopolítica, a Associação Halitinã. Assim, desde 2003, a Associação Halitinã exerceu a gestão da saúde, em convênio com a Funasa e a Sesai (SILVEIRA, 2011 ).

Borges (2009) descreve que o trabalho desenvolvido por essa associação, composta por atores dessa etnia indígena, foi positivo, articulado e efetivo. Sua área de atuação contemplava quarenta e nove aldeias e a população atendida era de 1.500 indígenas, em um território dividido em três áreas de abrangência, cada área atendida por uma equipe de saúde.

A Associação Halitinã investiu em capacitação de profissionais de saúde indígenas e não indígenas, incluindo verbas para viabilizar bolsas de estudo para a formação de jovens haliti-paresí na área da saúde e advocacia, promovendo, além das ações previstas na política nacional de atenção à saúde indígena, diversas medidas em atendimento aos seus objetivos e interesses (SILVEIRA, 2011).

Porém, após 2011, com a centralização dos convênios, as atividades da Associação Halitinã foram transferidas para a Associação Paulista para o Desenvolvimento da Medicina (SPDM). Assim, nesses últimos quatro anos, a assistência à saúde voltou a ser realizada de 
forma pontual e focada na doença. Os relatos constantes de falta de materiais, insumos e alta rotatividade de profissionais de saúde em todas as aldeias do território paresí, em consonância com os demais relatos das lideranças, comunidades e organizações indígenas de todo o Brasil, apontaram para o quadro de caos e calamidade em que se tornou o atendimento à saúde indígena brasileira (ALTINI et al., 2013).

Aspectos da demografia dos Haliti-Paresí: uma reflexão a partir do Censo 2010 do IBGE

O contingente populacional de 817.963 indígenas descritos pelo censo de 2010 apresentou um crescimento populacional no período 2000/2010 de 84 mil pessoas, representando 11,4\% (BRASIL, 2012a). A Região Centro-Oeste está entre as que apresentaram crescimento no volume populacional dos autodeclarados indígenas. Desde a última década do século passado vem ocorrendo no Brasil um fenômeno conhecido como "etnogênese" ou "reetinização". Nele, povos indígenas que, por pressões políticas, econômicas e religiosas ou por terem sido despojados de suas terras e estigmatizados em função dos seus costumes tradicionais, foram forçados a esconder e a negar suas identidades tribais como estratégia de sobrevivência, agora estão reassumindo e recriando as suas tradições indígenas (LUCIANO, 2006).

No Centro-Oeste estão $16 \%$ dos índios brasileiros, sendo que deste total a maioria reside em área rural. Mato Grosso possui 42.538 índios e apresentou uma taxa média geométrica de crescimento de $3,8 \%$, sendo $2,3 \%$ na zona urbana e $5,3 \%$ na zona rural (IBGE, 2012).

Os povos indígenas de Mato Grosso estão distribuídos em 65 etnias e/ou povos, dentre quais os Haliti-Paresí, que durante o censo de 2010 totalizaram 2.022 pessoas; 1.550 autodeclaradas e outros 472 que se consideraram como integrantes deste povo. Essa população reside em nove terras indígenas de Mato Grosso. Nas terras Ponte de Pedra, Juininha, Estivadinho e Figueiras residem exclusivamente pessoas dessa etnia. Como os Haliti-Paresí permitem a união de seus integrantes com outras etnias, em outras terras indígenas paresí residem também os Nambikwara, Rikebatsa, Irantxe e Arará do Pará, totalizando 2.886 
pessoas residentes nas terras indígenas dos Paresí, sendo 864 pertencentes às etnias anteriormente citadas (Figura 2).

Ao observar a população total é possível identificar que existe uma discreta predominância do sexo masculino $(52,7 \%)$. No entanto, na grande maioria das terras indígenas essa diferença é muito pequena, observando um equilíbrio na distribuição entre os sexos. Cabe ressaltar que para a terra indígena Estação Paresí não foram encontrados registros no referido censo, possivelmente pela mesma estar em análise judicial para sua homologação.

Figura 2 - Distribuição por sexo da população da etnia Paresí por terra indígena (2010).

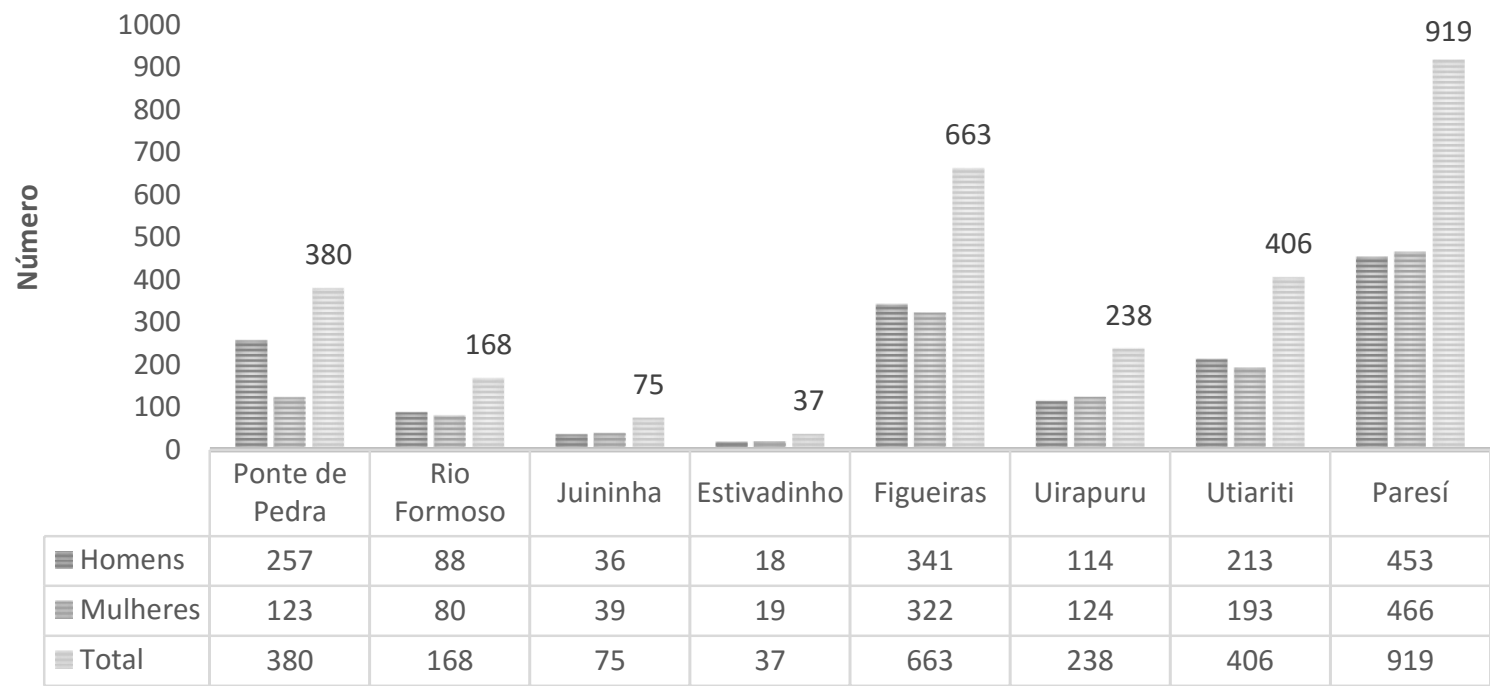

Fonte: Censo do IBGE (2010).

O português é língua fluente em todas as terras indígenas paresí, porém em sua grande maioria as comunicações acontecem também em língua indígena $(\mathrm{N}=1.172)$, predominando a língua aruak, coexistindo com as línguas bakairi e irantxe.

Fernandes e Costa (2014) descrevem que a preservação da cultura de um povo depende do mantimento de suas ideologias, tradições, costumes e principalmente de sua língua materna, pois na língua está presente sua história, como os antepassados se comunicavam, como nomeavam os seres e as coisas a sua volta, as lendas e crenças que motivaram suas vidas, e que como forma de identidade nacional deve ser passada de geração a geração. 
No Brasil, onde apenas $37,4 \%$ da população autodeclarada como indígena fala a língua de sua etnia, entre os Haliti-Paresí, 40,9\% preservam a língua, superando a média nacional. A língua materna desses grupos é a halití que tem como tronco a língua aruak, a mesma para todos os grupos haliti-paresí. Os grupos aruaque são culturas doadoras, ou seja, tendem a dominar ou influenciar os demais grupos, uma das características marcante entre os Haliti-Paresí. Os Aruaque foram os primeiros grupos indígenas a serem contatados por Cristóvão Colombo, na chegada ao continente americano, em 1492. Os grupos filiados à cultura aruaque possuem características que teriam agradado os europeus, como a natureza pacífica, hábitos sedentários e, sobretudo, por não comerem carne humana (SCHMIDT, 2011).

Paes (2002) descreve que a predominância da língua portuguesa entre os Haliti-Paresí pode estar relacionada à concepção de que os conhecimentos escolares em língua portuguesa podem fornecer subsídios para que os indígenas continuem seus estudos nas escolas da cidade, até mesmo cursando o ensino superior, de forma que no futuro tenham os seus advogados, juízes de direito, agrônomos, professores etc.

Assim, constroem a representação de que a língua portuguesa, por meio da escolarização nas aldeias, se constituirá no instrumento que viabilizará a inserção dos Haliti-Paresí nas mesmas condições dos não índios, em termos de status profissional e social.

Com relação à alfabetização, do total de 2.037 indígenas com idade superior a 10 anos que residem nas terras paresí, $81 \%$ são alfabetizados e superam a média nacional $(69,7 \%)$ e da Região CentroOeste $(76,9 \%)$ (IBGE, 2012). Porém, ao observamos a Figura 3, essa distribuição por terras indígenas demonstra que as regiões menos populosas (Estivadinho, Juininha, Rio Formoso, Ponte de Pedra e Uirapuru) possuem maiores índices de alfabetização em relação às terras indígenas com contingente populacional maior (Paresí, Figueiras e Utiariti).

No último censo escolar, realizado em 2005 pelo Ministério da Educação, foi identificado que existem 2.323 escolas indígenas com 163.773 alunos matriculados em todo o país. 
Sobre o perfil desses estudantes indígenas foi possível verificar uma predominância de estudantes do sexo masculino $(52,2 \%)$ em todos os níveis de ensino, e que $81,2 \%$ deles estão cursando o ensino fundamental de 8 e 9 anos de duração, com predominância nas três primeiras séries (BRASIL, 2007b).

Figura 3 - Distribuição da população da etnia Paresí maior de 10 anos em relação à alfabetização por terra indígena (2010).

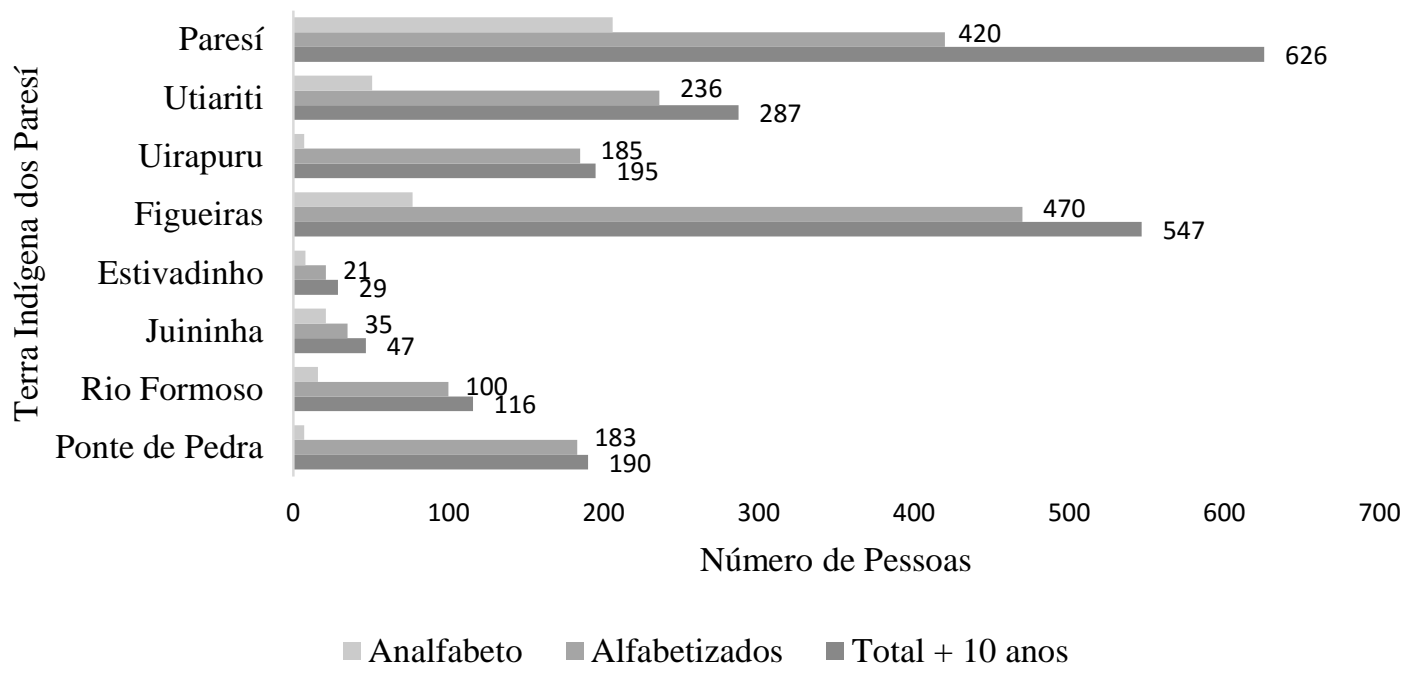

Fonte: Censo do IBGE (2010).

Neste mesmo estudo foi descrito que Mato Grosso conta com 176 escolas indígenas, 661 professores que atuam nas mesmas e 11.162 alunos matriculados em 2005. Seguindo o perfil nacional, a grande maioria desses alunos $(91,9 \%)$ está cursando o ensino fundamental.

A história da escolarização entre os Haliti-Paresí data da época de Marechal Rondon, por volta de 1920, quando, em missão de instalação das linhas telegráficas, fundou a primeira instituição escolar naquela região, o internato de Utiariti, organizada conforme princípios positivistas e que tinha como objetivo, entre outros, treinar os indígenas para o convívio com a "sociedade civilizada". Por volta de 1930, os jesuítas assumiram a escolarização na região, posteriormente executada por outras confissões religiosas, que, além da alfabetização em língua portuguesa, também tinham a missão de "salvar as almas indígenas" por meio da evangelização e da conversão a Cristo (PAES, 2002). 
No final dos anos de 1980, as prefeituras municipais da região assumiram a coordenação e acompanhamento das escolas indígenas, nas quais se implementavam as mesmas orientações e práticas pedagógicas das demais escolas de ensino fundamental do sistema municipal de educação.

Neste momento histórico, apenas a língua portuguesa era contemplada, contrapondo a Constituição federal de 1988, por seu artigo 210 , que preceitua "o ensino fundamental regular será ministrado em língua portuguesa, assegurada às comunidades indígenas também a utilização de suas línguas maternas e processos próprios de aprendizagem" (BRASIL, 1988). Apenas em 1996 dá-se início a um movimento de escolas diferenciadas na região, em que a língua portuguesa e a língua indígena foram implementadas no cotidiano das escolas haliti-paresí (PAES, 2002).

Em 2014, a Funai publicou uma cartilha sobre a importância do registro de nascimento entre os povos indígenas. Esta ação foi uma estratégia utilizada visando reduzir o subregistro identificado no censo de 2010 , pois apenas $67,8 \%$ da população indígena teve acesso ao registro do nascimento, enquanto que as demais raça/cor atingiram $98 \%$ (IBGE, 2012; FUNAI, 2014).

Embora o registro civil de nascimento não seja um documento obrigatório para as populações indígenas, a posse do mesmo oferece aos indígenas acesso aos direitos trabalhistas e previdenciários, além de possibilitar o ingresso em instituições de ensino e programas sociais, assim como a confecção da carteira de identidade, cadastro de pessoa física, carteira de trabalho e previdência social (FUNAI, 2014).

Entre os Haliti-Paresí, foram encontrados 745 indígenas que relataram ter registro de nascimento, destes $81,9 \%$ e $18 \%$ possuíam, respectivamente, $\mathrm{o}$ registro civil de nascimento e o Registro administrativo de Nascimento Indígena (RANI). Em 12\% dos indígenas nenhum tipo de registro foi identificado. Cabe ressaltar que não houve registros desta informação da Terra Indígena Estivadinho. Observa-se que os índices de registro nessa população é superior à média nacional e este fato pode estar relacionado à intensa relação que a comunidade tem com os não índios, sua integração e participação social nas políticas e ações em área urbana. 
O RANI não substitui o registro civil de nascimento, pois se trata de um documento administrativo emitido por funcionários da Funai desde 1973, quando foi institucionalizado pelo Estatuto do Índio. Em posse do RANI, o indígena pode realizar o registro civil de nascimento em situações em que não existem quaisquer registros, os indígenas podem procurar o cartório acompanhados de duas testemunhas e realizar o registro (FUNAI, 2014).

A questão econômica das comunidades indígenas é algo primordial a ser discutido, pois as atuais condições de vida enfrentadas pelos mesmos, na relação com a sociedade nacional e o mercado, causam transformações profundas nos contextos socioculturais em que estes povos estão inscritos, fazendo surgir, consequentemente, novas necessidades de consumo (BRASIL, 2012b). Para suprir essas necessidades, diversas são as atividades realizadas pelas populações indígenas como formas de geração de renda e de etnodesenvolvimento a partir dos seus saberes e práticas socioculturais.

Em 2010, a maioria da população brasileira apresentava uma renda entre meio e dois salários mínimos (50,6\%). Dos 2.232 indígenas dessa região que forneceram informações sobre renda, foi possível detectar que $50,5 \%$ deles não possuem nenhum tipo de renda, ratificando os dados publicados por silva e colaboradores, que chamaram a atenção para a desigualdade, a pobreza e a baixa renda das comunidades indígenas desde o censo de 2000 (SILVA, ARAUJO e SOUZA, 2002).

No presente estudo, do total dos indígenas que relataram ter renda, 37,2\% tinham renda entre meio e dois salários mínimos e apenas $9,5 \%$ possuem renda acima de 2 salários mínimos. Ao observamos essa distribuição por terra indígena paresí, é possível evidenciar que as rendas maiores do que dois salários mínimos estavam nas terras indígenas Ponte de Pedra e Uirapuru, seguidas pelos residentes da Terra Indígena Utiariti (Figura 4).

Nas demais terras indígenas incluídas na análise predominam a ausência de renda e baixa renda (de meio a 2 salários mínimos). Este fato pode estar relacionado às diferentes formas de comportamento dentro dessa etnia. Os subgrupos waimaré, kaxiniti, kozarini, warere e kawali realizam atividades cotidianas e econômicas distintas, sendo que 
os residentes em áreas com maior renda realizam parcerias e acordos econômicos com maior intensidade com a comunidade não indígena (SILVEIRA, 2011).

Figura 4 - Distribuição de renda em salários mínimos da população da etnia Paresí por terra indígena (2010).

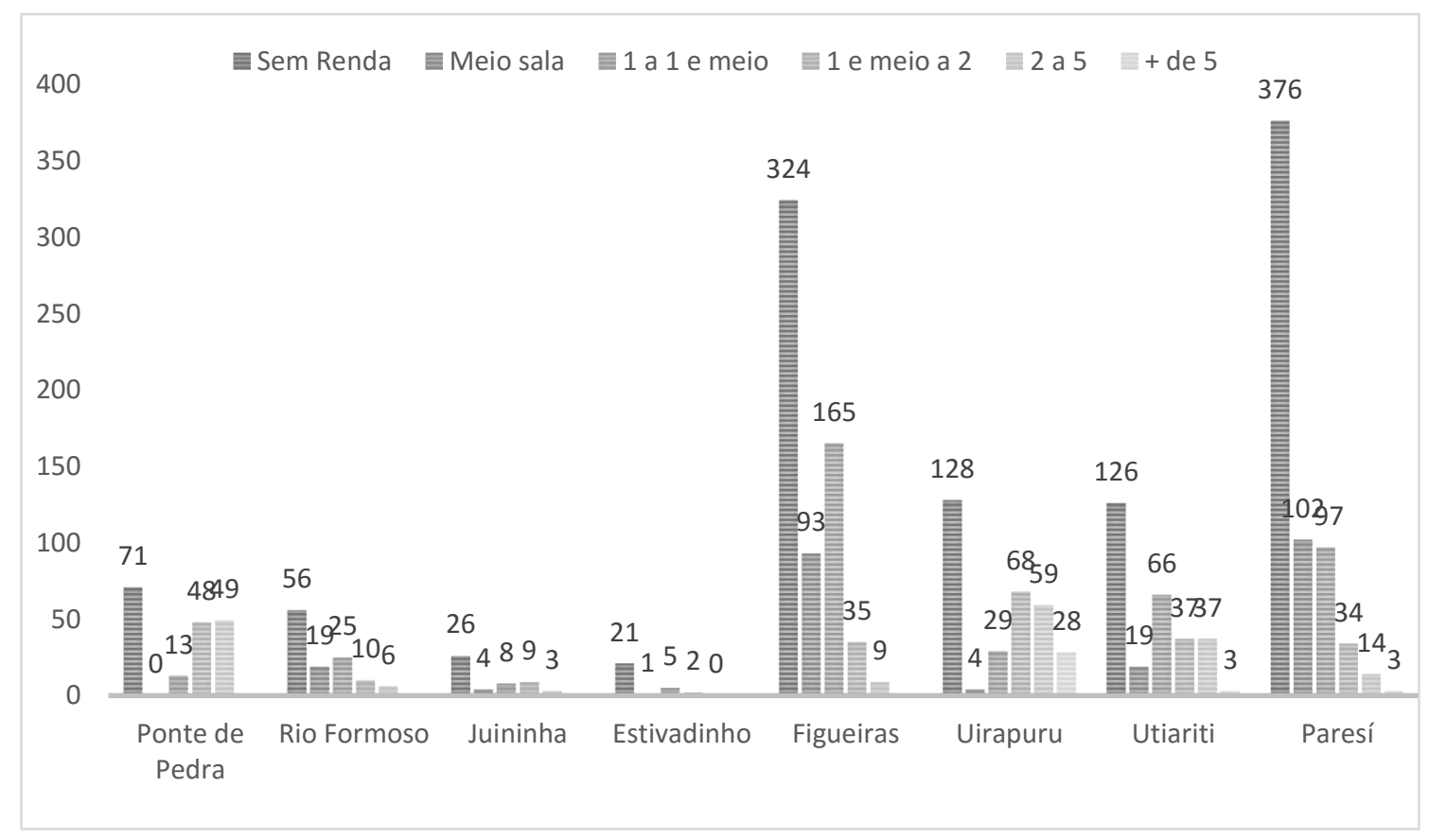

Fonte: Censo do IBGE (2010).

As condições de moradia dos povos indígenas é outra questão que precisa também ser amplamente discutida. As profundas modificações que a dinâmica cultural do contato com a população não indígena criaram levaram à emergência de novas necessidades, apontando para a necessidade de se discutir a importância de preservar as moradias tradicionais e adaptá-las às novas tecnologias ou de aderir aos tipos de moradia praticada nas regiões urbanas.

Em 2012, a Confederação da Agricultura e Pecuária do Brasil (CNA) realizou, em todas as regiões do país, um estudo com 1.222 indígenas em 32 aldeias com 100 habitantes ou mais com objetivo de conhecer o perfil populacional. Os resultados demonstraram que a maioria (61\%) dos índios viviam em moradias de madeira ou outro material que não de alvenaria, e que $68 \%$ avaliaram o local em que vivem, incluindo sua moradia, como ótimo ou bom (SENAR, 2015). 
O mesmo estudo identificou que em $78 \%$ das moradias dos índios havia energia elétrica, que $61 \%$ tinham água encanada e que apenas uma minoria deles (18\%) tinha banheiro dentro de casa, porém 55\% possuíam acesso a um banheiro fora do local em que vivem.

Nas terras indígenas haliti-paresí há predominância de moradias construídas de diferentes materiais (586) e apenas 123 casas tradicionais indígenas. A predominância de casas tradicionais foi identificada nas terras indígenas Paresí, Utiariti, Juininha e Rio Formoso, demonstrando que essas comunidades buscam manter a cultura e tradição arquitetônica de suas residências.

$\mathrm{O}$ acesso à moradia adequada é considerado um dos direitos humanos básicos e deve ser garantido a toda a população, principalmente ofertada às populações vulneráveis, como os povos indígenas, sem discriminação e em pé de igualdade com o restante da população, pois acesso à moradia adequada pode ser uma pré-condição para a realização de vários outros direitos humanos, incluindo o direito ao trabalho, à saúde, à segurança social, ao voto, à privacidade e à educação (BRASIL, 2013).

Luz a elétrica foi identificada na maioria das terras indígenas paresí, com exceção da Terra Indígena Estivadinho. O predomínio da luz elétrica nas residências dessas comunidades pode ser explicada pela expansão do Programa Luz para Todos, em que as propriedades rurais e indígenas foram contempladas nos últimos anos, propiciando a instalação de novas tecnologias nas aldeias.

A água que utilizam provém dos poços $(\mathrm{N}=401)$ e dos rios $(\mathrm{N}=247)$, e apenas em 18 residências a água de carro pipa é utilizada. Esses dados conflitam com a contextualização histórica dos HalitiParesí, uma vez que suas aldeias normalmente foram construídas na cabeceira de rios importantes da região, porém as transformações ambientais da região contribuíram para a redução na disponibilidade da água dessa malha hidrográfica, justificando-se a predominância de poços nessas terras indígenas.

$\mathrm{O}$ acesso ao banheiro foi descrito por 435 indígenas que residem nas terras indígenas paresí, enquanto que outros 299 relatam não ter acesso aos sanitários. A presença de banheiros no cotidiano das populações indígenas ainda é um desafio em decorrência de seus 
aspectos culturais, porém observa-se que a ampliação do acesso contribui sobremaneira para a melhoria das condições sanitárias e redução das doenças infecciosas e parasitárias.

Pena e Heller (2007) descrevem que muitas são as doenças que podem se proliferar devido à falta ou inadequação de medidas de saneamento. Fatores que contribuem para uma maior incidência ou prevalência de doenças são a não disponibilidade de água em quantidade e de boa qualidade, a má disposição dos dejetos e um inadequado destino dos resíduos sólidos. Esses autores ressaltam, ainda, que os investimentos em saneamento possibilitariam a redução da morbidade infantil por diferentes etiologias e que este cuidado com as comunidades indígenas é primordial para redução dos agravos decorrentes da falta de saneamento.

\section{Considerações finais}

O povo Haliti-Paresí demonstra, ao longo de todo seu processo histórico, uma interação e integração com as novas realidades que foram vivenciando, seja no contato com as diferentes culturas, seja nas pressões vivenciadas durante a perda de seu território até na luta pela reconstrução de suas origens e reestruturação de sua população.

Atualmente destacam-se pela organização social e política que possibilita um etnodesenvolvimento de sucesso na região, além da busca pela conservação de sua cultura e manutenção da qualidade de vida em consonância com os avanços nas relações que estabeleceram com os não índios.

As questões relacionadas à saúde expressam o misticismo e o cuidado holístico que é praticado e influenciado pela medicina tradicional indígena. Mesmo encontrando dificuldades em se sustentar ao longo de seu processo histórico, essas práticas se mantêm presentes no cotidiano dos Haliti-Paresí, que buscam atuar em complementaridade com a medicina ocidental.

O crescimento populacional reflete o processo de "etnogênese" no Brasil, uma vez que conseguiram se reestruturar em termos de 
contingente populacional a partir da década de 1990 e hoje somam mais de dois mil indivíduos, sendo a maioria do sexo masculino $(52,7 \%)$.

O português é língua fluente em todas as terras indígenas paresí e reflete o processo histórico educacional que vivenciaram, porém a preservação das línguas tradicionais $(40,9 \%)$ foi superior à média nacional, com predomínio da língua aruak, coexistindo com as línguas bakairi e irantxe. É preciso destacar que a alfabetização das pessoas com mais de 10 anos é de $81 \%$, com o maior número de alfabetizados nas terras indígenas menos populosas.

$81,9 \%$ possuíam o registro civil de nascimento, demonstrando ainda uma fragilidade nos registros, porém uma realidade superior aos índices brasileiros em comunidades indígenas.

A distribuição de renda ainda é uma realidade negativa, tendo em vista que $50,5 \%$ dessa comunidade relatou não ter renda, estando, assim, em risco de pobreza. As condições de moradia retratam duas realidades: em algumas terras indígenas há predominância de casas construídas de diferentes materiais, já em outras são mais frequentes as edificações tradicionais. A luz elétrica é acessível em todas as terras, exceto na Terra Indígena Estivadinho, enquanto a água potável provém predominantemente de poços, fatos estes que demonstram as diferentes adaptações dos subgrupos haliti-paresí.

A análise demográfica de uma etnia, quando realizada pautada em dados secundários por terras indígenas que residem, pode ser considerada como frágil, pois essa informação retrata não somente os dados dos Haliti-Paresí, mas também os dados de pessoas de outras etnias e não índios que, em decorrência do casamento inter étnico, passam então a residir nesses territórios.

Novas abordagens necessitam ser implementadas a fim de se conhecer os aspectos demográficos das comunidades indígenas, tendo em vista que a dinâmica de suas relações sociais, culturais e territoriais está em amplo crescimento e suscita uma descrição e análise que possa, de fato, contribuir para um amplo diagnóstico que direcione as ações políticas visando à melhoria da qualidade de vida dessas populações. 


\section{Referências bibliográficas}

ALTINI, Emília et al. A Política de Atenção À Saúde Indígena no Brasil: breve recuperação histórica sobre a política de assistência à saúde nas comunidades indígenas. Brasília: Conselho Indigenista Missionário, 2013.

ATHIAS, Renato. Diversidade étnica, direitos indígenas e políticas públicas. Recife: NEPE/UFPE, 2005.

ATHIAS, Renato; MACHADO, Marina. A saúde indígena no processo de implantação dos Distritos Sanitários: temas críticos e propostas para um diálogo interdisciplinar. Cad. Saúde Pública, Rio de Janeiro, v. 17, n. 2, p. 425-431, 2001.

BORGES, Juliano Luis. Política de Saúde Indígena e sua Aplicabilidade Entre o Povo Paresi - Mato Grosso/Brasil. IV Jornada Internacional de Políticas Públicas, São Luis, 2009.

BORTOlETTO, Renata. Morfologia Social Paresi: uma etnografia das formas de sociabilidade em um grupo Aruak do Brasil Central. 1999. 136 f. Dissertação (Mestrado em Filosofia e Ciências Humanas) - Unicamp, São Paulo, [1999].

Oloniti e o castigo da festa errada: relações entre mito e ritual entre os paresi. Revista Cadernos de Campo USP, São Paulo, n. 13, p. 91-100, 2005.

BOTELHO, João Bosco, COSTA, Hideraldo Lima da: Pajé: reconstrução e sobrevivência. História, Ciências, Saúde, Rio de Janeiro, v. 13, n. 4, p. 927-56, 2006.

BRASIL. Constituição da República Federativa do Brasil - 1988. Brasília: Senado, 1988.

Ministério da Saúde. Fundação Nacional de Saúde. Política Nacional de Atenção a Saúde dos Povos Indígenas. Brasília: Ministério da Saúde, 2002.

. Ministério da Saúde/Fundação Nacional de Saúde. A visão da Funasa. Brasília: Assessoria de Comunicação e Educação em Saúde, 2006.

$2007 \mathrm{a}$.

Fundação Nacional de Saúde. Portaria n. 2.656/GM/MS, de 17 de outubro de

Instituto Nacional de Estudos e Pesquisas Educacionais Anísio Teixeira.

Estatísticas sobre educação escolar indígena no Brasil. Brasília: Instituto Nacional de Estudos e Pesquisas Educacionais, 2007b.

Instituto Brasileiro de Geografia e Estatística (IBGE). Os indígenas no censo demográfico 2010: primeiras considerações com base no quesito cor ou raça. Rio de Janeiro: Ministério do Planejamento, Orçamento e Gestão, Instituto Brasileiro de Geografia e Estatística, Diretoria de Pesquisas, 2012a. 
Ministério da Cultura. Secretaria da Identidade e da Diversidade Cultural. Plano Setorial para as Culturas Indígenas/ MinC/ SCC. Brasília: Ministério da Cultura, 2012b.

Secretaria de Direitos Humanos da Presidência da República. Direito à moradia adequada. Brasília: Coordenação Geral de Educação em SDH/PR, Direitos Humanos, Secretaria Nacional de Promoção e Defesa dos Direitos Humanos, 2013.

BRITO, Carolina Arouca Gomes de; LIMA, Nísia Trindade. Medicina e antropologia: a saúde no Serviço de Proteção aos Índios (1942 -1956). Boletim do Museu Paraense Emílio Goeldi, Belém, v. 8, n. 1, p. 95-112, 2013.

BUCHILLET, Dominique. Medicina tradicional e medicina ocidental na Amazônia. Belém: CEJUP, 1991.

CANOVA, Loiva. Doces bárbaros: imagens dos índios Paresi no contexto da conquista portuguesa em Mato Grosso (1719-1757). 2001. 105 f. Dissertação (Mestrado em História) - UFMT, Cuiabá, [2001].

COSTA FILHO, Aderval. Mansos por Natureza: situações históricas e permanência paresi. 1996. 216 f. Dissertação (Mestrado em Antropologia) - Universidade de Brasília, Brasília, [1996].

COSTA, Romana Maria. Cultura e Contato: um estudo da sociedade paresi no contexto das relações interétnicas. 1985. 198 f. Dissertação (Mestrado em Antropologia Social) - UFRJ, Rio de Janeiro, [1985].

FERNANDES, Patrícia Damasceno; COSTA, Natália Sierra Assencio. A Importância das Línguas Indígenas no Brasil. Web-Revista Sociodialeto, Campo Grande, v. 5. n. 13, p. 34-47, 2014.

FERREIRA, Luciane Ouriques. A emergência da medicina tradicional indígena no campo das políticas públicas. História, Ciências, Saúde, Rio de Janeiro, v. 20, n. 1, p. 203-219, 2013.

FUNAI - Fundação Nacional do Índio. O Brasil Indígena. Brasília: FUNAI, 2010.

Registro Civil de nascimento para os povos indígenas no Brasil. Secretaria de Direitos Humanos. Fundação Nacional do Índio. Brasília: Ministério da Justiça, 2014.

GARNELO, M. Luiza; PONTES, Ana Lúcia (Org.). Saúde Indígena: uma introdução ao tema. Brasília: MEC-SECADI, 2012.

IBGE - Instituto Brasileiro de Geografia e Estatística. Censo demográfico. 2010. Disponível em: http://indigenas.ibge.gov.br/tt Acesso em: 02 mar. 2015. 
Os indígenas no censo demográfico de 2010. Rio de Janeiro: IBGE, 2012.

LUCIANO, Gersen S. O índio brasileiro: o que você precisa saber sobre os povos indígenas no Brasil de hoje. Brasília: Ministério da Educação, Secretaria de Educação Continuada, Alfabetização e Diversidade - SECAD em parceria com o Museu Nacional, Laboratório de Pesquisas em Etnicidade, Cultura e Desenvolvimento - LACED, 2006.

MACHADO, Maria Fátima R. Índios de Rondon: Rondon e as linhas telegráficas na visão dos sobreviventes Waimaré e Kaziniti, grupos Paresi. 1994. 2 v. Tese (Doutorado em Antropologia) - UFRJ, Rio de Janeiro, [1994].

MARTINS, André Luiz. Política de saúde indígena no Brasil: reflexões sobre o processo de implementação do Subsistema de Atenção à Saúde Indígena. 2013. 126 f. Dissertação (Mestrado em Saúde Pública) - Escola Nacional de Saúde Pública, Rio de Janeiro, [2013].

MORAIS, Rosa Maria G. (Org.). Projeto "Piloto I": DST e Aids, formação aos índios Paresi das terras indígenas Utiariti, Juininha e Rio Formoso. Cuiabá: Universidade Federal de Mato Grosso/Instituto de Ciências Humanas e Sociais/Departamento de Geografia, 2003.

OLIVEIRA, Carlos Edinei de. Famílias e Natureza: as relações entre família e ambiente na colonização de Tangará da Serra. Cuiabá: Sanches Ltda, 2004.

PAES, Maria Helena Rodrigues. A questão da língua na escola indígena em aldeias Paresi de Tangará da Serra-MT. Revista Brasileira de Educação, Rio de Janeiro, n. 21, p. 52-60, 2002.

PAGLIARO, Heloisa; AZEVEDO, Marta Maria; SANTOS, Ricardo Ventura. Demografia dos Povos Indígenas no Brasil. Rio de Janeiro: Fiocruz/Abep, 2005.

PENA, João Luiz; HELLER, Léo. Perfil sanitário: as condições de saneamento e de habitação na Terra Indígena Xakriabá, Minas Gerais. Revista de Estudos e Pesquisas, Brasília, v. 4, n. 1, p. 213-254, 2007.

PEREIRA, Adalberto H. O pensamento mítico do Paresi (Primeira parte): Pesquisas, Antropologia. São Leopoldo: Instituto Anchietano de Pesquisas, 1986.

O pensamento mítico do Paresi (Segunda parte): Pesquisas, Antropologia. São Leopoldo: Instituto Anchietano de Pesquisas, 1987.

RONDON, Cândido Mariano S. História natural: etnographia. Comissão de linhas telegráficas de Mato Grosso ao Amazonas, 1910.

ROQUETTE-PINTO, Edgard. Rondônia: anthropologia - ethnografia. Rio de Janeiro: Fiocruz/Academia Brasileira de Letras, 2005. 
SÁ, Mario. O universo mágico das curas: o papel das práticas mágicas e feitiçarias no universo do Mato Grosso setecentista. História, Ciências, Saúde, Rio de Janeiro, v. 16, n. 2, p. 325-344, 2009.

SANTOS, Ricardo Ventura et al. Saúde dos Povos Indígenas e Políticas Públicas no Brasil. In: GIOVANELLA et al (Org.). Políticas e Sistema de Saúde no Brasil. Rio de Janeiro: Fiocruz, 2008. p. 33-55.

SCHMIDT, Max. Os aruaques: uma contribuição ao problema da difusão cultural. Brasília: mimeo, 2011.

SENAR. Perfil dos índios no Brasil. Brasília, 2015. Disponível em: http://www.canaldoprodutor.com.br/terrasdobrasil/perfil-dos-indios-no-brasil/. Acesso em: 20 out. 2015.

SILVA, Frederico A. Barbosa da; ARAUJO, Herton Ellery; SOUZA, Andre Luís. Diagnóstico da situação das populações indígenas do Brasil. Brasília: IPEA, 2002.

SILVEIRA, Ema Maria dos Santos. Cultura Como Desenvolvimento Entre Os Paresi Kozarini. 2011. 159 f. Dissertação (Mestrado em Antropologia Social) - UFRN, Natal, [2011].

TERÇAS, Ana C. P.; ATANAKA, M.; LEMOS, E. R. S. Projeto de pesquisa: Situação de Saúde dos Paresí. Universidade Federal de Mato Grosso, 2014.

Recebido em: 07/12/2015* Aprovado em: 29/04/2016 * Publicado em: 30/06/2016 